\title{
Characterization of Phytophthora nicotianae Resistance Conferred by the Introgressed Nicotiana rustica Region, Wz, in Flue-Cured Tobacco
}

Kestrel L. McCorkle, ${ }^{\dagger}$ Department of Plant Pathology, North Carolina State University, Raleigh, NC 27695; Katherine Drake-Stowe and Ramsey S. Lewis, Department of Crop and Soil Science, North Carolina State University, Raleigh, NC 27695; and David Shew, Department of Plant Pathology, North Carolina State University, Raleigh, NC

\begin{abstract}
Black shank, caused by Phytophthora nicotianae, is one of the most important diseases affecting tobacco worldwide and is primarily managed through use of host resistance. An additional source of resistance to $P$. nicotianae, designated as $W z$, has been introgressed into Nicotiana tabacum from $N$. rustica. The $W z$ gene region confers high levels of resistance to all races, but has not been characterized. Our study found $W z$-mediated resistance is most highly expressed in the roots, with only a slight reduction in stemlesion size in $\mathrm{Wz}$ genotypes compared with susceptible controls. No substantial relationships were observed between initial inoculum levels and disease

development on $W z$ genotypes, which is generally consistent with qualitative or complete resistance. Isolates of $P$. nicotianae adapted for five host generations on plants with the $W z$ gene caused higher disease severity than isolates adapted on $W z$ plants for only one host generation. $W z$-adapted isolates did not exhibit increased aggressiveness on genotypes with other sources of partial resistance, suggesting pathogen adaptation was specific to the $W z$ gene. To reduce potential for pathogen population shifts with virulence on $W z$ genotypes, $W z$ should be combined with other resistance sources and rotation of varying black shank resistance mechanisms is also recommended.
\end{abstract}

Black shank, caused by the soilborne oomycete Phytophthora nicotianae, is one of the most important diseases affecting tobacco production in the United States and other tobacco producing areas of the world (Lucas 1975). Symptoms include wilting, chlorosis, necrosis of the roots and basal part of the stem, and eventually plant death. The disease typically begins in soils above $20^{\circ} \mathrm{C}$ following periods of rainfall that allow soil saturation needed for the release of asexual, motile zoospores (Shew 1983). Zoospores are the primary infectious propagules of $P$. nicotianae, and can be produced every $72 \mathrm{~h}$ on infected roots under favorable environmental conditions (Gallup et al. 2006; Lucas 1975; Shew and Lucas 1991). The pathogen is therefore capable of producing high levels of secondary inoculum within a single growing season that increases its potential to quickly adapt to selection pressures such as host resistance. While pathogen populations and the disease are managed through chemical applications, crop rotation, and cultural practices, planting of resistant varieties is the most effective way to decrease black shank disease severity worldwide (Lucas 1975) and is a critical tool to integrate into a comprehensive disease management strategy.

Two types of host resistance have been used in the development of modern flue-cured tobacco cultivars. Quantitative resistance, derived from the cigar tobacco cultivar Florida 301 (Fla 301) and often referred to as 'Fla 301 resistance,' is controlled by multiple genes and is partial and non-race specific (Chaplin 1966; Smith and Clayton 1948; Xiao et al. 2013). Florida 301 was derived from a cross between varieties Big Cuba and Little Cuba by Tisdale in the 1930s (Tisdale 1931). Varieties with Fla 301 resistance exhibit low to high levels of root resistance, but little or no stem and leaf resistance to $P$. nicotianae (Jones and Shew 1995; Shew and Lucas 1991; Wernsman et al. 1974). Some level of disease loss occurs with all varieties with this type of resistance, and there is a strong tendency for it to be associated with lower yields and reduced leaf quality. Additional sources of partial resistance are therefore being investigated for incorporation into breeding programs.

Similar to Fla 301, cigar tobacco variety Beinhart 1000 (BH 1000) also exhibits a high level of resistance to all races of $P$. nicotianae. To our knowledge, this cultivar has not been used in the parentage of any current flue-cured varieties, due to unfavorable leaf chemistry characteristics associated with resistance (Vontimitta and Lewis 2012a, b).

${ }^{\dagger}$ Corresponding author: Kestrel L. McCorkle; E-mail: krlannon@ncsu.edu

Accepted for publication 23 September 2017.

C) 2018 The American Phytopathological Society
BH 1000 originated from a selection of variety Quin Diaz, and possesses a high level of root resistance with little to no expressed resistance in leaf or stem tissues (Chaplin 1966; Heggestad and Lautz 1957; Nielsen 1992; Tedford and Nielsen 1990; Wills and Moore 1971). Two major-effect quantitative trait loci (QTL), Phn 7.1 and $P h n$ 15.1, were previously identified from BH 1000 that explained $43 \%$ of the observed variation in resistance (measured as end percent survival) in a BH $1000 \times$ Hicks doubled haploid mapping population (Vontimitta and Lewis 2012a, b). Both Phn 7.1 and $P h n 15.1$ contribute to a reduced rate of lesion expansion and a subsequent delay in above-ground symptom development (McCorkle et al. 2013). The Phn 7.1 QTL is present in both Fla 301 and BH 1000, but Phn 15.1 only contributes to black shank resistance in BH 1000 (Xiao et al. 2013). This newly identified Phn 15.1 QTL found in $\mathrm{BH} 1000$ provides another source of partial resistance that might be used to increase black shank resistance if it can be incorporated into tobacco varieties with acceptable yield levels and cured leaf quality (Vontimitta and Lewis 2012a, b).

Genes conferring complete resistance also have been used to manage black shank. Complete resistance to wild-type (race 0) $P$. nicotianae is conferred by single genes, $P h p$ and $P h l$. The $P h p$ gene was transferred to N. tabacum from N. plumbaginifolia (Chaplin 1962), while the $P h l$ gene was transferred to $N$. tabacum from $N$. longiflora (Valleau et al. 1960). Host resistance conferred by the Php gene is expressed in tobacco roots, stems, and leaves (Csinos 1999). In response to widespread deployment of the $P h p$ gene in flue-cured varieties desired by growers, there was a rapid race shift from race 0 to race 1 in production fields (Csinos and Bertrand 1994; Gallup and Shew 2010; Sullivan et al. 2005b). Race 1 is able to overcome both $P h p$ and $P h l$ (Lucas 1975), and is the dominant race where varieties containing the $P h p$ gene have been planted.

Multiple races of $P$. nicotianae have been reported and include races $0,1,2$, and 3. Race 2 was reported in South Africa using KY $14 \times \mathrm{L} 8$, Burley $21 \times$ L8, and Delcrest 202 as a set of differentials, but has not been widely accepted because no known resistance gene is present in Delcrest 202 (Gallup and Shew 2010; van Jaarsveld et al. 2002). Race 3, which overcomes $P h l$ but not the Php gene, was first described in Connecticut by McIntyre and Taylor and later reported in North Carolina (Gallup and Shew 2010; McIntyre and Taylor 1976, 1978). Similar to disease resistance controlled by single genes in other pathosystems, the black shank pathogen is able to quickly overcome complete resistance in field environments (Apple 1962, 1967; Csinos and Bertrand 1994; Gallup and Shew 2010; Sullivan et al. 2005b).

A new source of black shank disease resistance was introgressed from $N$. rustica into $N$. tabacum and designated as $W z$ (Drake and 
Lewis 2013; Woodend and Mudzengerere 1992). Wz confers very high levels of resistance to both race 0 and race 1 of $P$. nicotianae while having little negative impact on tobacco yield and/or quality (Drake et al. 2015). These characteristics make this source of resistance potentially very desirable for increasing the level of black shank resistance in fluecured tobacco. It is not currently known, however, whether $\mathrm{Wz}$ confers complete resistance or a high level of partial resistance.

While the use of host resistance can provide an efficient way to reduce economic losses due to plant pathogens, pathogen populations can quickly adapt to selection pressure applied by changes in management strategies. When complete resistance is continuously used in the same location, selection pressure is imposed to select for individuals in the pathogen population that are able to infect the host. This selection results in a pathogen race shift, giving single gene resistance greatly reduced value in disease management (McDonald and Linde 2002). Complete resistance is rarely durable, and although partial resistance is generally considered durable, it can be difficult to utilize in breeding programs. Pathogen adaptation to partial resistance does occur, but usually occurs gradually, resulting in an erosion of resistance over time as opposed to the rapid breakdown of complete resistance characterized by boom and bust cycles (McDonald and Linde 2002).

Research on pathogen adaptation to partial resistance by root pathogens is generally lacking, with most studies having focused on foliar fungal pathogens. Previous research outside of the tobacco black shank pathosystem have reported an overall increase in pathogen aggressiveness characterized by increases in secondary inoculum production (Delmotte et al. 2014; Phillips and Blok 2008), increased lesion expansion and infection efficiency (Leonard 1969; Villaréal and Lannou 2000), decreases in latent period (Lehman and Shaner 1997), and erosion of partial resistance over time (Montarry et al. 2012). Studies on fungi, viruses, and nematodes support observations of increased pathogen aggressiveness in populations exposed to host varieties with high levels of partial resistance when compared with populations exposed to susceptible hosts (Cowger and Mundt 2002; Dukes and Apple 1961; Leonard 1969; Montarry et al. 2012; Phillips and Blok 2008; Sullivan et al. 2005b). In the tobacco black shank pathosystem, pathogen adaptation to partial resistance derived from Fla 301 has been observed (Dukes and Apple 1961; McCorkle et al. 2015; Sullivan et al. 2005a, b).

Because $W z$ resistance has not been characterized, and $P$. nicotianae has the genetic ability to quickly overcome complete resistance, several research objectives were pursued. The objectives of this study were to determine 1) if $\mathrm{Wz}$ resistance is expressed both in tobacco stem and root tissues, 2) if black shank resistance conferred by the $W z$ region can be overcome by high pathogen inoculum densities, and 3 ) if $P$. nicotianae can rapidly adapt to $W z$-mediated resistance.

\section{Materials and Methods}

Genetic materials. The genetic materials used in the experiments described below were as follows. First, K 326 was selected as an elite flue-cured tobacco cultivar with low levels of polygenic black shank resistance. This variety was also used as the recurrent parent in the development of the $\mathrm{Wz}$ homozygous line, $\mathrm{K} 326 \mathrm{Wz} / \mathrm{Wz}\left(\mathrm{BC}_{5} \mathrm{~F}_{3}\right.$ stage of backcrossing) and the $\mathrm{K} 326 \mathrm{Wz} /-\mathrm{F}_{1}$ hybrid (heterozygous for $\mathrm{Wz}$ mediated resistance). Experimental materials also included Hicks (a variety highly susceptible to black shank), NC 1071 (a breeding line carrying the Php gene coupled with extremely low levels of any additional resistance), K 346 (a flue-cured cultivar with a moderate to high level of partial resistance likely derived from Fla 301), $\mathrm{BH}$ 1000 (a cigar line with exceptionally high levels of partial resistance), and K 326 Php/Php (K 326 into which Php was backcrossed five times).

Stem resistance. Stems of six tobacco genotypes (K $326 \mathrm{Wz} / \mathrm{Wz}$, K 326 Wz/-, K 326 Php/Php, K 326, Hicks, and NC 1071) were inoculated with either a race 0 or race 1 isolate of $P$. nicotianae in a controlled greenhouse environment to determine if $W z$ resistance is expressed in aboveground tissue. The initial isolates F11-12-2 (race 0) and F11-16-4 (race 1) were obtained from soil in the black shank disease nursery at the Upper Coastal Plain Research Station in Rocky Mount, $\mathrm{NC}$, by suspending $1 \mathrm{~g}$ infested soil in $25 \mathrm{ml}$ sterile deionized water over five Petri dishes containing a semiselective PARPH medium
(Sullivan et al. 2005a). The PARPH medium contained 5\% clarified V8 juice as the basal medium and was amended with pentachloronitrobenzene, hymexazol, ampicillin, rifampcin, and pimiricin (Kannwischer and Mitchell 1978; Shew 1983). The dishes were incubated at room temperature for $48 \mathrm{~h}$, and then the soil was washed from the agar surface and individual colonies were transferred to fresh PARPH. The isolate race was confirmed based on inoculations of host differential varieties Hicks, KY 14xL8, and NC 71 (Gallup and Shew 2010). Isolates causing symptoms only on Hicks are race 0 , while those causing symptoms on all three varieties are race 1. Isolates that cause symptoms on the susceptible variety Hicks and on KY $14 \times$ L 8 containing the $P h l$ gene, but not on NC 71 containing the Php gene, have been described as race 3 (Gallup and Shew 2010). The race 0 and 1 isolates were selected based on the initial high level of aggressiveness on varieties with Fla 301 resistance. $P$. nicotianae isolates were grown in pure culture on a $5 \% \mathrm{~V} 8$ agar medium for 7 to 12 days at $28^{\circ} \mathrm{C}$. V8 agar medium was made by adding $20 \mathrm{~g}$ Bacto Agar (Fisher Scientific, Fair Lawn, NJ) to $800 \mathrm{ml}$ of deionized water and $200 \mathrm{ml}$ of clarified V8 juice. Medium was autoclaved at $121^{\circ} \mathrm{C}$ for $30 \mathrm{~min}$, then $18 \mathrm{ml}$ of medium was poured into each $10 \mathrm{~cm}$ Petri dish after it cooled to $56^{\circ} \mathrm{C}$. Sterilized toothpicks were placed on the surface of the $P$. nicotianae cultures and incubated in the dark for an additional 7 days. Sterilized toothpicks were prepared by cutting rounded wooden toothpicks (Home360 distributed by DZA Brands, LLC) in half and autoclaving them in $5 \% \mathrm{~V} 8$ broth for $30 \mathrm{~min}$ at $121^{\circ} \mathrm{C}$ three consecutive times prior to placing on the agar culture.

Seeds from each of the six tobacco genotypes were germinated on autoclaved Metro Mix 200 growing medium (Sun Gro Horticulture, Agawam, MA) under plastic domes in a growth chamber maintained at a temperature of approximately at $25^{\circ} \mathrm{C}$ with $24 \mathrm{~h}$ fluorescent light. Approximately 2 weeks after emergence, seedlings were transplanted to individual $15-\mathrm{cm}$ pots containing a $2: 1$ peat/sand mixture. Plants were inoculated with infested toothpicks approximately 6 weeks after transplanting when a minimum height of $30 \mathrm{~cm}$ was reached. Toothpicks were inserted into the plant stems between the fourth and fifth node and noninfested toothpicks were used as controls. Treatments were arranged in a split-plot design with race as the main plot factor and host genotype as the subplot factor. Subplots consisted of five plants and the experiment was replicated three times. Lesion lengths were measured with a digital caliper each day for 5 days postinoculation and area under lesion expansion curve (AULEC) was calculated for each plant. Analyses of variance for AULEC values were conducted using PROC MIXED of SAS 9.3 (SAS Institute, Cary, NC). Race, genotype, and race by genotype interaction were considered as fixed effects, while run and replication within run were considered random effects. Comparisons of lesion expansion between genotypes were calculated with LSMEANS using a Tukey-Kramer adjustment (Kramer 1956).

Initial inoculum study. To determine if high initial inoculum levels could overcome the resistance observed in $W z$ genotypes, the six genotypes used in the stem inoculation trial were inoculated in an inoculum dosage study. Cultures of the same race 0 and race 1 isolates of $P$. nicotianae used for the stem resistance study were grown under the same parameters as previously described. Once hyphae reached the edge of the Petri dish, sterilized oat grains were placed directly on top of cultures. Dishes were then sealed with Parafilm and incubated at room temperature in the dark for approximately 15 days. Oat grains were first sterilized by combining $500 \mathrm{ml}$ of crimped oats with $400 \mathrm{ml}$ of deionized water and autoclaving at $121^{\circ} \mathrm{C}$ for $1 \mathrm{~h}$ daily for three consecutive days.

Seeds from each of the six tobacco genotypes were germinated on autoclaved Metro Mix 200 growing medium (Sun Gro Horticulture, Agawam, MA) under plastic domes in a growth chamber maintained at a temperature of approximately $25^{\circ} \mathrm{C}$ with $24 \mathrm{~h}$ fluorescent light. Approximately 2 weeks after emergence, seedlings were transplanted to individual $10-\mathrm{cm}$ pots containing a $2: 1$ peat/sand mixture. One week after transplanting, each plant was inoculated with one of five dosage levels $(1,5,10,15$, or 20 oat grains) of either race 0 or race 1 by placing the prescribed number of oat grains uniformly into the soil equidistant from the plant stem and $1.5 \mathrm{~cm}$ deep. Treatments were 
arranged in a split-plot design with the race/dose combination as the main plot factor and genotype as the subplot factor. Subplots consisted of six plants and the experiment was replicated three times in a growth chamber in the NCSU Applied Tobacco Genetics and Chemistry laboratory.

The growth chamber was maintained at a temperature of approximately $30^{\circ} \mathrm{C}$ with $24 \mathrm{~h}$ light, and uniform soil moisture was maintained via subirrigation. Subplots consisted of six plants, each in an individual 8-cm pot (LA 1801, Landmark Plastics, Inc., Akron, OH). Disease incidence was recorded each day for 45 days postinoculation, and area under disease progress curve (AUDPC) was calculated for each subplot according to Madden et al. (2007). Analyses of variance for AUDPC values were performed using PROC MIXED of SAS 9.3. Genotype, race, dose, and all interactions between the three classes were treated as fixed effects, and replication was treated as a random effect. Comparisons between treatments were made using LSMEANS with Tukey-Kramer adjustments for the $P$ values (Kramer 1956).

Pathogen adaptation. The same race 0 and race 1 isolates of $P$. nicotianae selected for the stem and root resistance studies were used for the adaptation study. Isolates were adapted on plants of $\mathrm{K} 326 \mathrm{Wz} /-$ for five consecutive cycles of selection by inoculating K $326 \mathrm{Wz} /$-plants and then reisolating from the plant (one of 10 replicant plants per generation) with the shortest incubation period to serve as inoculum for the next generation of selection (McCorkle 2016). Plants were inoculated by placing two infested oat grains in 5-cm-deep holes $3 \mathrm{~cm}$ away from the plant stem on either side. To reisolate the pathogen, small pieces of host tissue about $1 \mathrm{~cm}^{2}$ in size were taken from the leading edge of necrotic tissue and disinfested in a $10 \%$ bleach ( $0.8 \%$ sodium hypochlorite) solution for $1 \mathrm{~min}$. Samples were rinsed in sterile deionized water and placed on dry paper towels to remove excess water. Pieces of tissue were then placed on PARPH medium and incubated at $28^{\circ} \mathrm{C}$ for 2 days in the dark. A small piece of hyphal tissue from the colony edge was transferred to subsequent PARPH plates until the isolate was in pure culture, then stored on a 5\% V8 medium. The most aggressive isolate from generations one (G1) and five (G5) of selection from each race (total of four isolates) were then used to inoculate five tobacco genotypes (Hicks, $\mathrm{K}$ $326 \mathrm{Wz} /-, \mathrm{K} 326 \mathrm{Wz} / \mathrm{Wz}, \mathrm{K} 346$, and $\mathrm{BH} 1000$ ) to characterize the nature of isolate adaptation to $W z$ and other sources of black shank resistance. Inoculum for the four isolates was prepared as previously described to select adapted isolates with increased aggressiveness. Plants were inoculated with four infested oat grains per pot by placing two oat grains in each 5-cm-deep hole $3 \mathrm{~cm}$ on either side of each plant stem. Plants were watered after inoculation to seal holes.

Five tobacco genotypes were sown on a 1:1 mixture of peat-lite and sand in $10 \mathrm{~cm} \times 15 \mathrm{~cm}$ plastic cell packs in Phytotron growth chambers (NC State campus). Genotypes included Hicks, K 346, BH 1000, $\mathrm{K} 326 \mathrm{Wz} /-$, and K $326 \mathrm{Wz} / \mathrm{Wz}$. Seedlings were watered daily and fertilized once per week with 10-10-10 Miracle-GRO fertilizer (Scotts Miracle-Gro Company, Marysville, $\mathrm{OH}$ ). Plants were grown at $30 / 26^{\circ} \mathrm{C}$ day/night temperature with fluorescent lighting at an intensity of $750 \mu \mathrm{mol} \cdot \mathrm{m}^{-2} \cdot \mathrm{s}^{-1}$ for $14 \mathrm{~h}$ per day. Six- to seven-week-old seedlings were transplanted to $10-\mathrm{cm}$ plastic pots and grown for an additional 4 weeks at the same environmental conditions as above. Colonized oat grains were used to inoculate eight seedlings of each genotype 4 weeks after transplanting by placing one colonized oat grain into each of two 5-cm-deep holes $3 \mathrm{~cm}$ away from the stem. Plants were watered after inoculation to seal inoculum holes.

Treatments were organized in a randomized complete block design with each isolate host genotype combination replicated eight times in each of two runs of the experiment. For race 0 and race 1 inoculations, each treatment block corresponded to a single growth chamber cart. Carts were moved daily to access all plants for watering and rating. A noninoculated susceptible Hicks plant was placed on each cart to ensure inoculum was not being transferred from one treatment to adjacent treatments.

Plants were rated at approximately the same time daily for the development of stem necrosis or significant wilting. The incubation period (time in days from inoculation to the development of aboveground symptoms) was recorded for 4 weeks postinoculation. Not all plants developed symptoms within the 4 -week test period, so incubation period in days was converted to disease severity values for comparison across varieties. The assigned severity values for each class were as follows: plants that became symptomatic on days 1 to $6=10,7$ to 10 days $=8,11$ to 16 days $=6,17$ to 22 days $=4,23$ to 28 days $=2$, and no symptoms at day $28=0$. On day 28 of the experiment, plant roots were rinsed in water and percent root rot was visually rated by the same evaluator for all runs of the experiment. Disease severity and root rot means were calculated in SAS (Version 9.4, SAS Institute, Cary, NC), and an analysis of variance (ANOVA) table was generated using the PROC GLIMMIX command. Race 0 and race 1 experiments were analyzed separately.

\section{Results}

Stem resistance. A significant run effect was observed for the stem inoculation experiment $(P<0.0001)$ due to variations in overall disease development across all treatments for each run, but data were analyzed across runs because the same trends were observed for each run. Significant differences were observed between host genotypes for AULEC with race 0 inoculations $(P<0.0001)$, with the susceptible variety Hicks having the highest AULEC, and lines with the Php source of single gene resistance (NC 1071 and K 326 Php/Php) the lowest AULEC (Fig. 1). In contrast, the K $326 \mathrm{Wz} / \mathrm{Wz}$ and $\mathrm{K} 326$ $W z$ - genotypes developed substantial stem lesions when inoculated with both races. No significant differences in AULEC were observed between the $\mathrm{K} 326 \mathrm{Wz} / \mathrm{Wz}$ homozygote and the $\mathrm{K} 326 \mathrm{Wz} /$ - heterozygote, but both had AULEC values lower than Hicks inoculated with the race 0 isolate (Fig. 1). No significant differences were observed among genotypes for AULEC values after inoculations with race 1 (Figs. 1 and 2). In contrast to $P h p$ containing genotypes (NC 1071 and K 326 Php/Php), which had low levels lesion expansion when inoculated with race 0 and significant lesion expansion when inoculated with race $1, W z$ genotpyes (K $326 \mathrm{Wz} /$ - and $\mathrm{K} 326 \mathrm{Wz} / \mathrm{Wz}$ ) developed substantial stem lesions after inoculation with either race.

Initial inoculum study. The effects of genotype and genotype $x$ pathogen race interaction were significant $(P<0.0001)$, but no genotype $\times$ race $\times$ dose interaction was observed $(P=0.7046)$. No significant run effect was observed so data were analyzed across runs. Hicks exhibited the highest AUDPC value with race 0 inoculations, with similar AUDPC values observed among all inoculum doses (Fig. 3). No significant differences were observed between dosage levels for any individual genotype. AUDPC values were much lower on $W z$-containing genotypes than on the susceptible Hicks, but were similar for both $W z$-containing genotypes across all dosage levels (Fig. 3). In contrast, lines with Php single gene resistance (K 326 Php/Php and NC 1071) exhibited no disease development. With race 1, Hicks and NC 1071 exhibited the greatest AUDPC values, while $\mathrm{K} 326 \mathrm{Wz} / \mathrm{Wz}$ and $\mathrm{K} 326 \mathrm{Wz} /$ - had the lowest. Similar to race 0 treatments, low amounts of disease were observed on $W z$ genotypes, although no differences were observed with the range of inoculum level tested (Fig. 3).

Pathogen adaptation. For the $P$. nicotianae adaptation experiment, no significant run $\times$ isolate-generation interaction was detected for disease severity for either race, and data were pooled over runs for analysis. Disease severity trends across all host genotypes were the same for both race 0 and race 1 inoculations (Figs. 4 and 5). High levels of disease developed after race 0 and race 1 inoculations of the susceptible variety Hicks. Most aboveground black shank symptoms in Hicks plants occurred by 6 days after inoculation. This contrasted with the low disease severity values after inoculation with either isolate for the resistant genotypes K 346 and BH 1000 (Figs. 4 and 5). For both race treatments, no significant differences were observed in disease severity between G1 and G5 isolates for the genotypes Hicks, $\mathrm{K} 346$, or BH $1000(P>0.05)$ (Figs. 4 and 5).

For the $\mathrm{K} 326 \mathrm{Wz} /$ - and $\mathrm{K} 326 \mathrm{Wz} / \mathrm{Wz}$, genotypes, disease severities were low after inoculations with G1 isolates, but significantly higher $(P<0.0001)$ after inoculations with either the G5 isolates of race 0 and race 1 (Figs. 4 and 5). K $326 \mathrm{Wz} /-$ exhibited an increase in mean disease severity from 0.4 when inoculated with the G1 race 0 isolate, to a mean severity of 3.8 when inoculated with the G5 race 0 isolate. Similarly, for race 0 inoculations of $\mathrm{K} 326 \mathrm{Wz} / \mathrm{Wz}$, mean 
disease severity increased from 0.5 for $\mathrm{G} 1$ inoculations to 3.6 for G5 inoculations (Fig. 4). This large increase in disease severity over five generations of selection was also observed for K $326 \mathrm{Wz} /$ - and $\mathrm{K} 326$ $W z / W z$ genotypes for race 1 inoculations $(P<0.0001)$. Disease severity for $\mathrm{K} 326 \mathrm{Wz} /$ - inoculated with race 1 increased from 0.0 to 4.1 with isolates from G1 and G5, respectively. Similarly, disease severity for $\mathrm{K} 326 \mathrm{Wz} / \mathrm{Wz}$ increased from 1.1 to 4.5 with isolates from $\mathrm{G} 1$ and G5, respectively.

No significant run $\times$ isolate-generation interaction was observed for percent root rot, so data from both runs was pooled for analysis. Percent root rot trends across all host genotypes were the same for both race 0 and race 1 inoculations (Figs. 6 and 7). A high percentage of root rot was observed for susceptible variety Hicks, with all plants exhibiting $100 \%$ root necrosis, regardless of race or isolate generation. Overall, varieties K 346 and BH 1000 exhibited lower amounts of root rot as compared with Hicks for race 0 and race 1 inoculations (Figs. 6 and 7). For both races, simple effect comparisons of host genotype $\times$ isolategeneration combinations revealed no differences in percent root rot between G1 and G5 inoculations for Hicks, K 346, or BH $1000(P>$ 0.05) (Figs. 6 and 7). In contrast, for $\mathrm{K} 326 \mathrm{Wz} /-$ and $\mathrm{K} 326 \mathrm{Wz} / \mathrm{Wz}$, significantly greater $(P<0.05)$ amounts of root rot were observed on plants inoculated with the G5 isolates as compared with the G1 isolates for both races. For genotype $\mathrm{K} 326 \mathrm{Wz} /$-inoculated with race 0, percent root rot increased from $21 \%$ with the G1 isolate to $49 \%$ with the G5 isolate. For the same genotype inoculated with race 1, percent root rot increased from $11 \%$ with the G1 isolate to $63 \%$ with the G5 isolate.

\section{Discussion}

Both partial and complete sources of host resistance have been important tools in the management of black shank in tobacco since introduction of the pathogen into the United States around 1915. Cigar tobacco variety Fla 301 is the primary source of partial resistance for commercial tobacco varieties and has been heavily relied upon in disease management systems, particularly since widespread pathogen race shifts beginning in the 1990s (Csinos and Bertrand 1994; Gallup and Shew 2010; Sullivan et al. 2005a, b; Tisdale 1931).

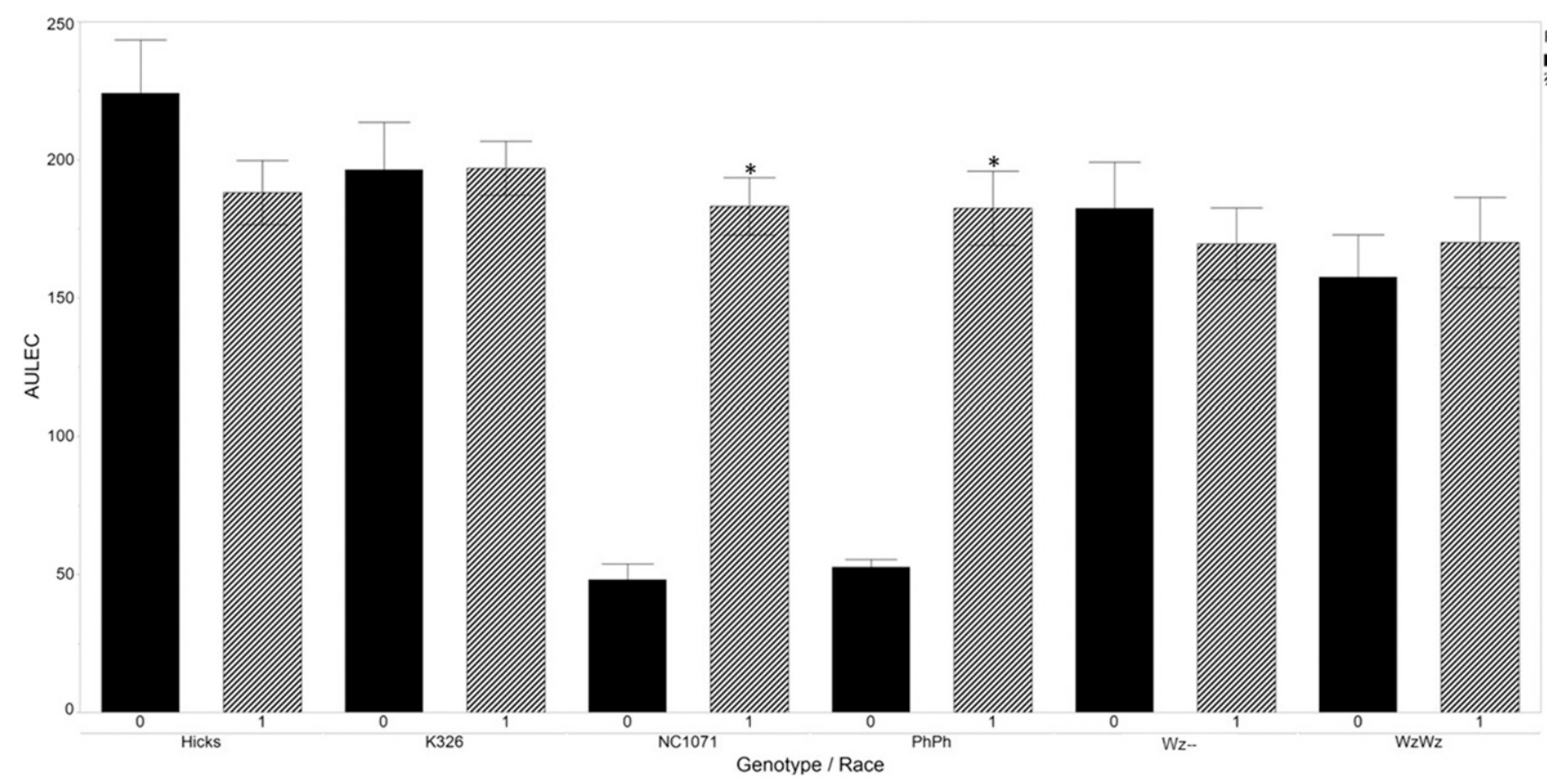

Fig. 1. Black shank area under lesion expansion curve (AULEC) for race 0 and race 1 Phytophthora nicotianae stem inoculations of tobacco genotypes Hicks, K326, NC 1071, K326 $\mathrm{PhPh}, \mathrm{K} 326 \mathrm{Wz} /$-, and K326 Wz/Wz. Significant differences between race 0 and race 1 inoculations for each variety are indicated by "*".

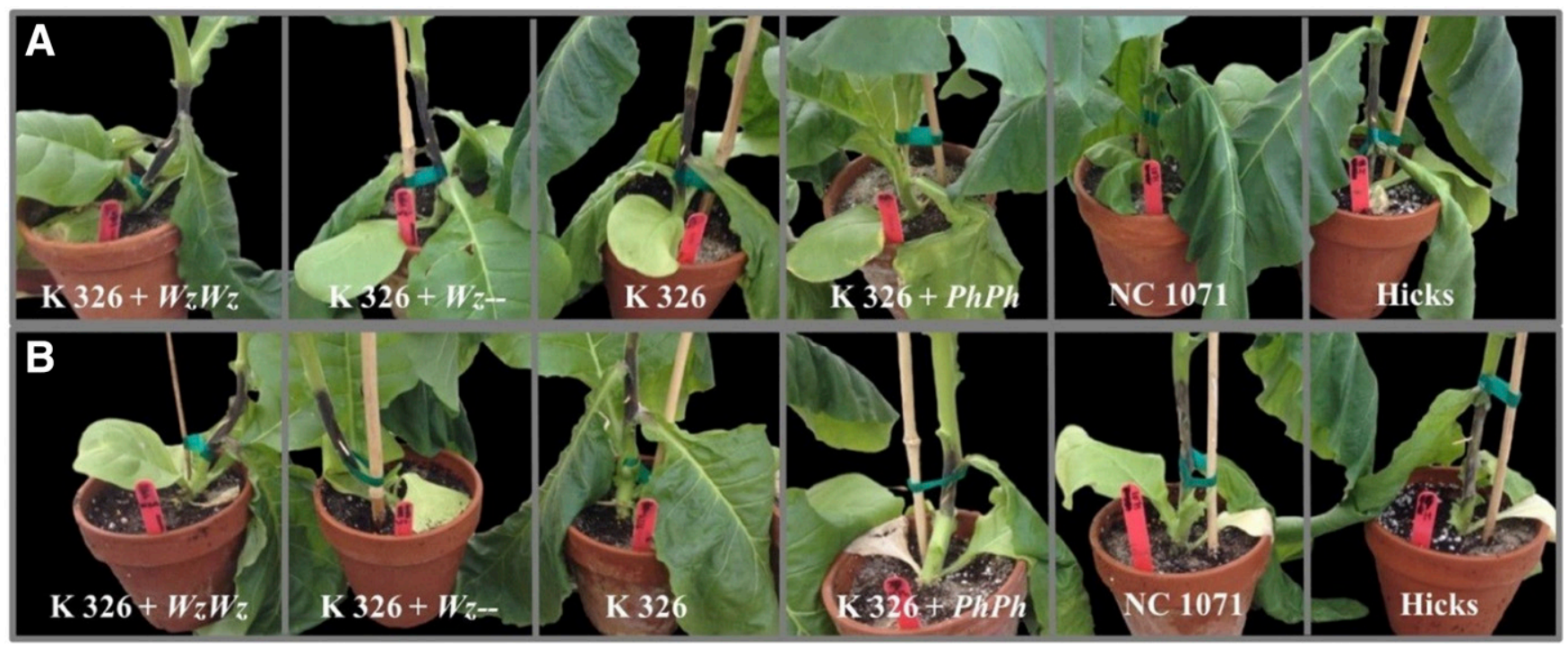

Fig. 2. Stem inoculations using an infested toothpick inoculation method on tobacco varieties with race $0(\mathbf{A})$ and race 1 (B) isolates of Phytophthora nicotianae. 
In this study, we investigated features of $W z$-mediated resistance, a type of resistance that may be of value for increasing the level of black shank resistance in future flue-cured tobacco cultivars. First, we were interested in determining the similarity of $W z$ to the dominant $P h p$ gene in terms of expression of resistance in stem tissues (Wills and Moore 1971). For race 0 stem inoculations, we confirmed the high level of stem resistance in Php-containing genotypes NC 1071 and K 326 $P h p / P h p$ as evidenced by the low level of lesion expansion. In contrast, significant lesion expansion was observed on $P h p$ genotypes when inoculated with race 1 , which can overcome $P h p$ and $P h l$ genes. In contrast, $W z$ genotypes (K $326 \mathrm{Wz} /$ - and $\mathrm{K} 326 \mathrm{Wz} / W z$ ) developed substantial stem lesions after inoculation with either race 0 or race 1. The lack of stem resistance in Wz genotypes differs from the genefor-gene resistance conferred by the $P h p$ gene, but it is similar to low stem resistance of plants with complete resistance controlled by the Phl gene (Wills and Moore 1971).
In partially resistant varieties of tobacco, black shank disease development is highly dependent upon initial inoculum levels (Ferrin and Mitchell 1986). If initial inoculum levels are high, $P$. nicotianae is capable of causing severe disease even on varieties with high levels of partial resistance (Lucas 1975). High inoculum levels create more potential infections on plant roots, especially under favorable environmental conditions. A higher number of lesions can compensate for the reduced lesion size typical of resistant varieties compared with susceptible varieties. In contrast, high levels of disease can occur on susceptible varieties at much lower inoculum levels due to higher pathogen infection efficiencies and greater rates of lesion expansion compared with more resistant plants (Ferrin and Mitchell 1986; Gallup et al. 2006). Varieties with complete resistance from the $P h p$ or $P h l$ genes are immune to infections from race 0 of $P$. nicotianae at all inoculum levels, but race 1 can cause high levels of damage with low initial inoculum concentrations unless high levels of partial resistance are also

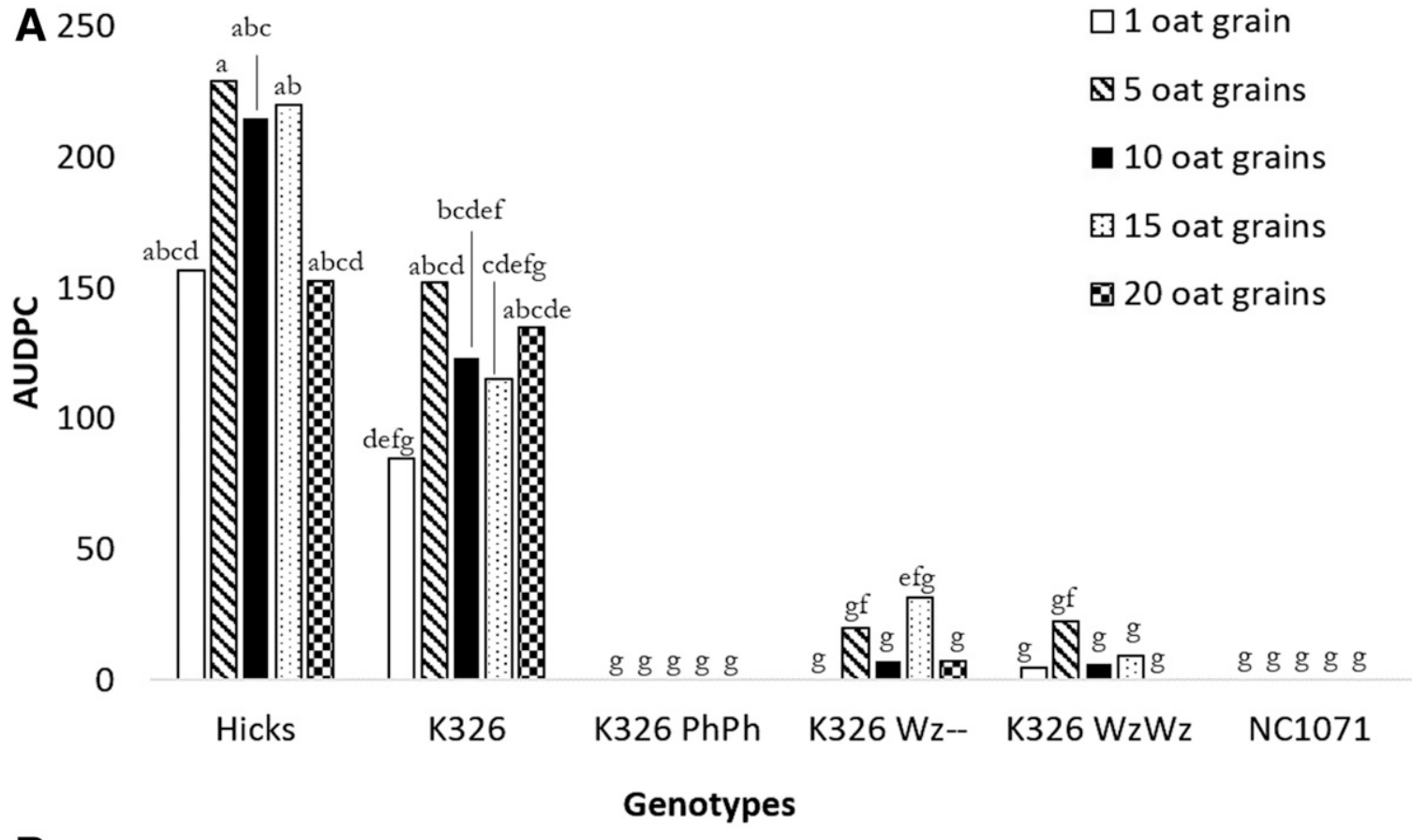

B

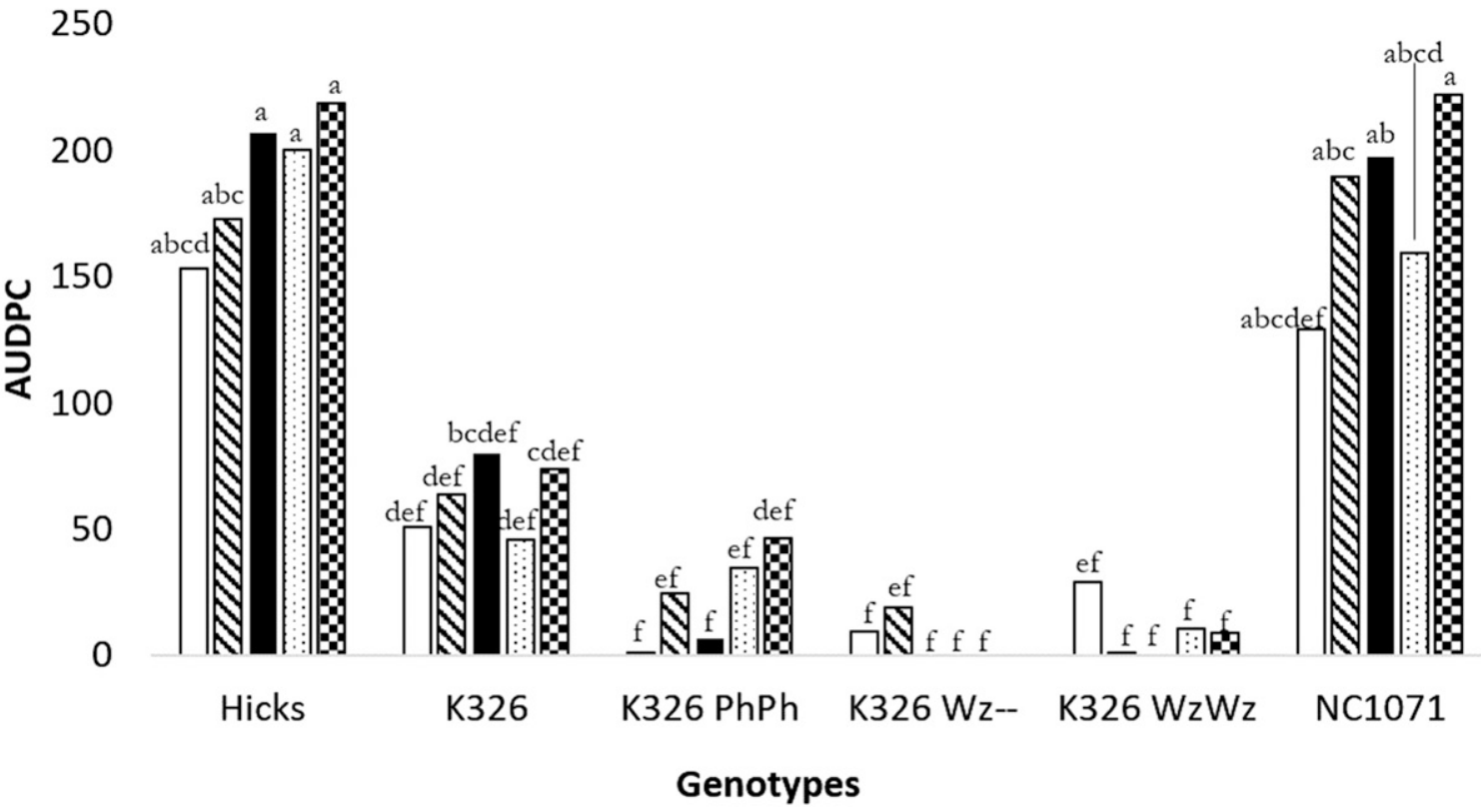

Fig. 3. Black shank area under disease progress curve (AUDPC) for race 0 (A) and race 1 (B) inoculations with five levels of inoculum dose. Comparison between means was done using Tukey-Kramer adjustment. 
incorporated into the variety. Partial resistance is controlled by multiple genes with additive effects, so increasing levels of inoculum are typically associated with increased disease severity (McDonald and Linde 2002).

To better understand the nature of resistance conferred by the $W z$ gene region, we compared tobacco genotypic responses when exposed to $1,5,10,15$, and 20 oat grains infested with either a race 0 or race 1 isolate of $P$. nicotianae. For race 0 inoculations, no plants of
Php-containing genotypes exhibited disease symptoms. In contrast, for both race 0 and race 1 inoculations, small amounts of disease were observed on $W z$-containing genotypes. These observations are inconsistent with $W z$ providing resistance via an immunity mechanism. However, no relationships were observed between initial inoculum levels and the amount of disease development on any of the genotypes tested, including K 326 . The variety K 326 has a low level of partial resistance, so disease can be observed even at low initial inoculum levels, which

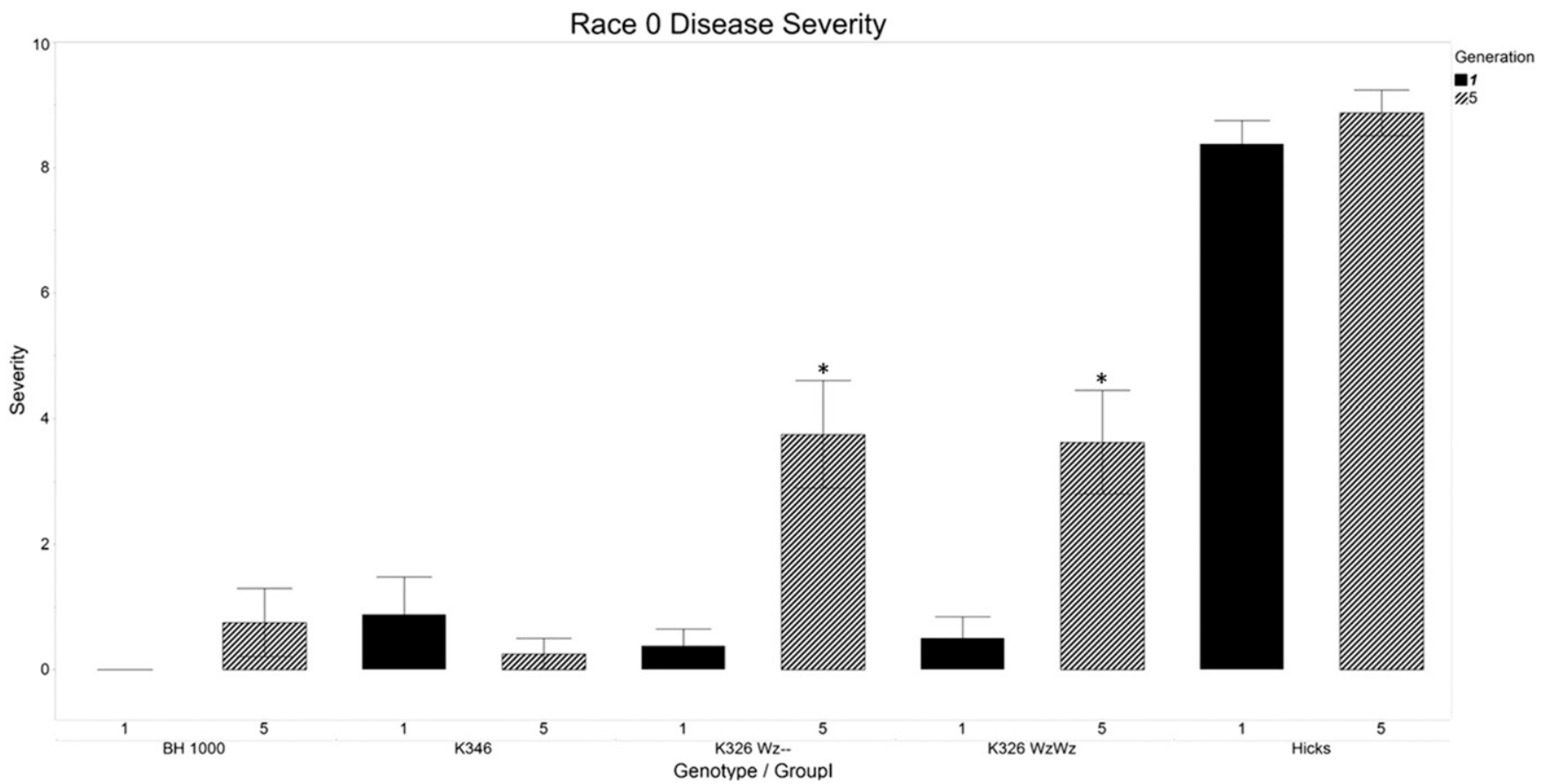

Fig. 4. Mean disease severity $(n=16)$ of tobacco varieties Hicks, K346, K326 Wz/-, K326 Wz/Wz, and Beinhart 1000, following inoculation with a race 0 Phytophthora nicotianae isolate exposed to host genotype K326 Wz/-for one (G1) and five generations (G5). Disease severity values assigned by incubation period in days. Severity value of 10 for 0 to 6 days, 8 for 7 to 10 days, 6 for 11 to 16 days, 4 for 17 to 22 days, 2 for 23 to 28 days, and 0 for no aboveground symptoms 28 days postinoculation. Significant differences between $\mathrm{G} 1$ and $\mathrm{G} 5$ inoculations for each variety are indicated by “*”.

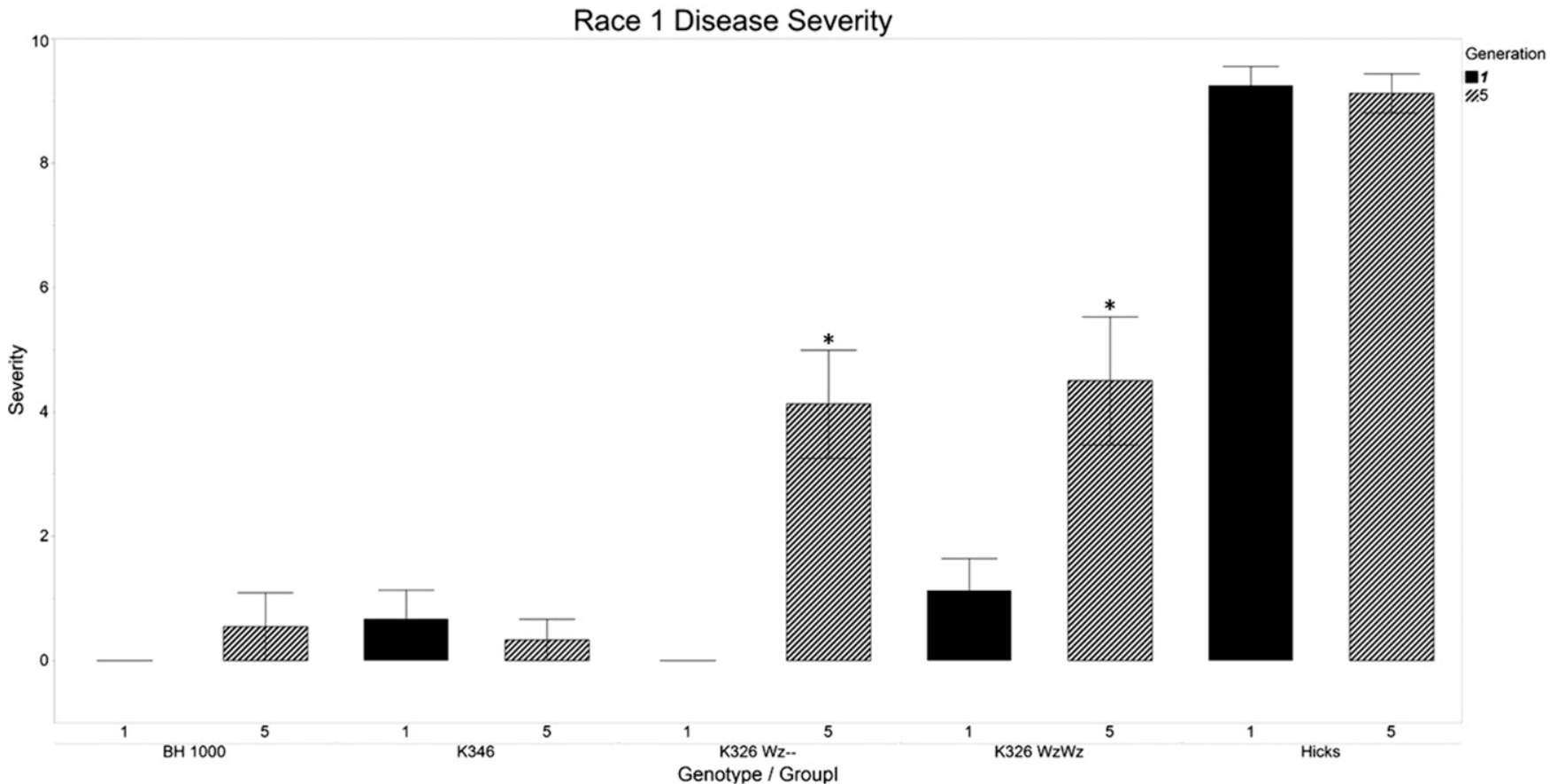

Fig. 5. Mean disease severity $(n=16)$ of tobacco varieties Hicks, K346, K326 Wz/-, K326 Wz/Wz, and Beinhart 1000, following inoculation with a race 1 Phytophthora nicotianae isolate exposed to host genotype K326 Wz/- for one (G1) and five generations (G5). Disease severity values assigned by incubation period in days. Severity value of 10 for 0 to 6 days, 8 for 7 to 10 days, 6 for 11 to 16 days, 4 for 17 to 22 days, 2 for 23 to 28 days, and 0 for no aboveground symptoms 28 days postinoculation. Significant differences between $\mathrm{G} 1$ and G5 inoculations for each variety are indicated by "*”. 
could be one reason for not observing the typical increase in disease severity with increasing initial inoculum associated with partially resistant varieties. Also, no evidence of an additive effect associated with increasing zygosity of $\mathrm{Wz}$ was observed. Based solely upon growth chamber inoculation data, it is difficult to draw conclusions on whether $W z$ confers complete resistance versus a high level of partial resistance.

Black shank disease resistance conferred by the $W z$ region is likely controlled by a single gene, although the presence of multiple favorable genes on the alien introgressed $N$. rustica segment cannot be ruled out. Pathogen adaptation to $W z$ genotypes was investigated after five generations of pathogen selection for aggressiveness/ virulence on $W z$ genotypes. In controlled inoculation experiments involving $\mathrm{G} 1$ and $\mathrm{G} 5$ isolates adapted on $\mathrm{Wz}$ genotypes, no differences in the level of disease or root rot were observed on Hicks, K 346, or BH 1000 , which have resistance to black shank from other genetic sources. In contrast, large differences were observed in how $W z$ genotypes responded to the adapted isolates of both races. These results clearly

\section{Race 0 Root Rot}

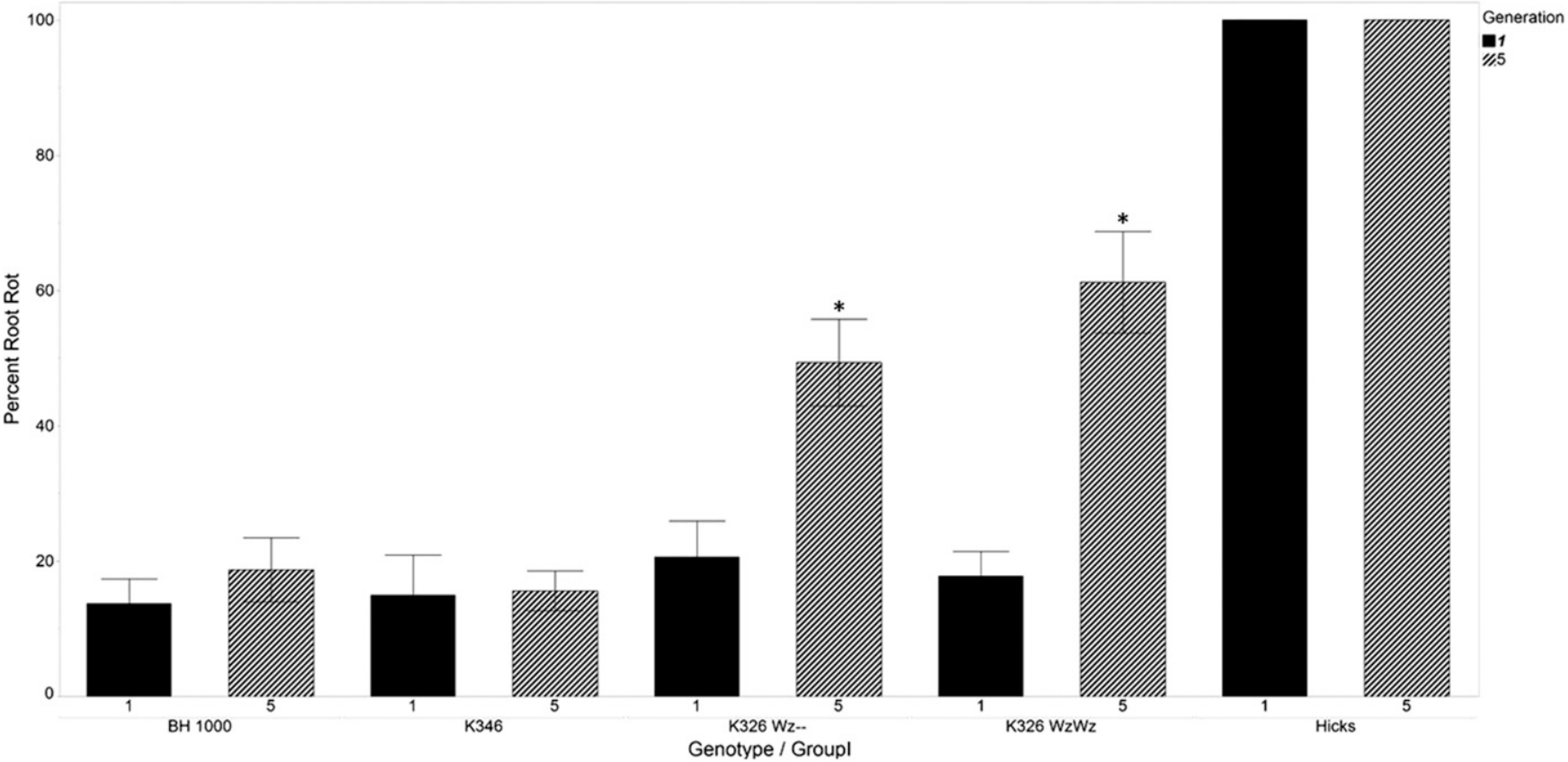

Fig. 6. Mean percent root rot $(n=16)$ of tobacco varieties Hicks, K346, K326 Wz/-, K326 Wz/Wz, and Beinhart 1000, following inoculation with a race 0 Phytophthora nicotianae isolate exposed to host genotype K326 Wz/- for one (G1) and five generations (G5). Percent root rot was rated manually 28 days post inoculation on a scale of 0 to 100 . Significant differences between $\mathrm{G} 1$ and $\mathrm{G} 5$ inoculations for each variety are indicated by "*”.

\section{Race 1 Root Rot}

100

80

20

0

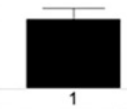

BH 1000

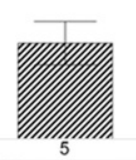

5
Race 1 Root Rot

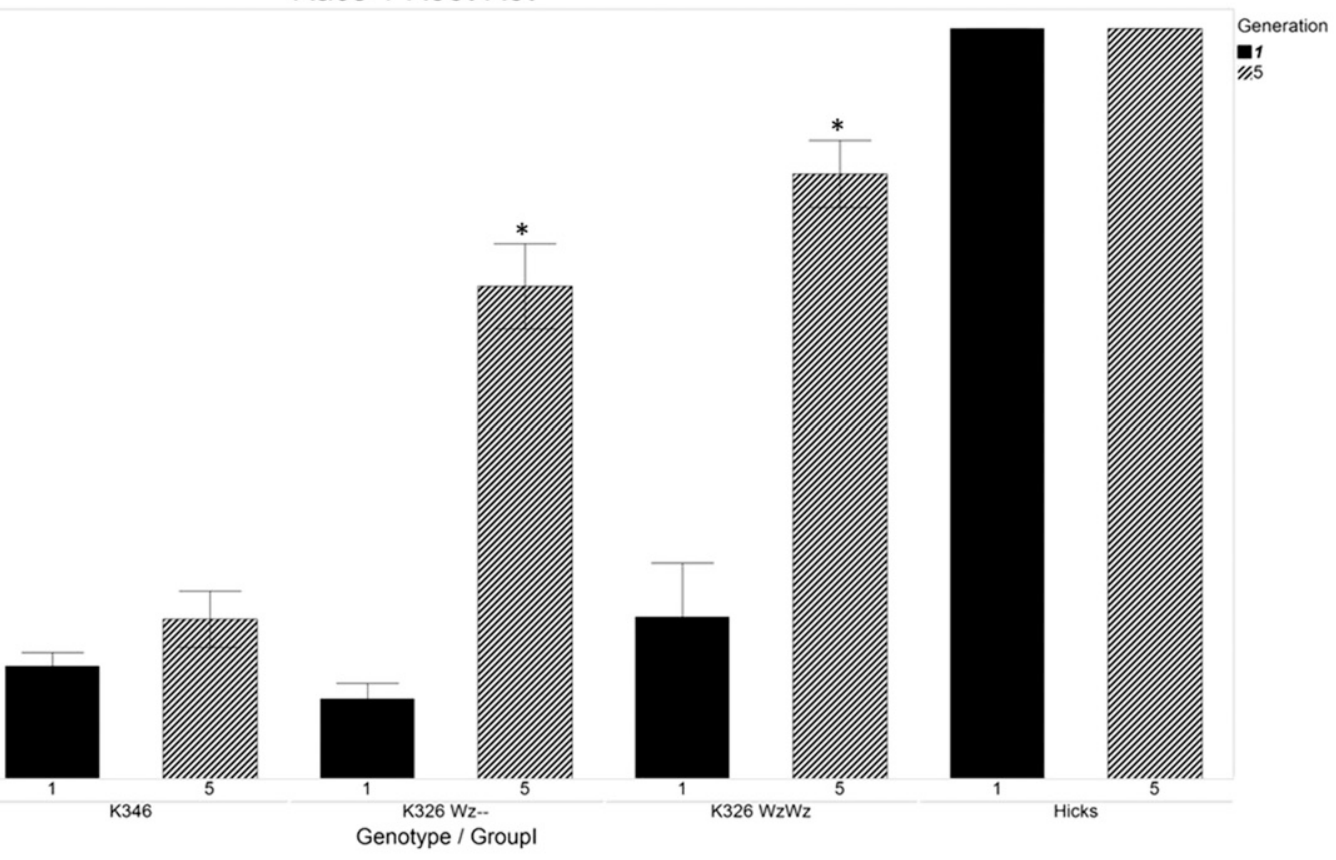

Fig. 7. Mean percent root rot $(n=16)$ of tobacco varieties Hicks, K346, K326 Wz/-, K326 Wz/Wz, and Beinhart 1000, following inoculation with a race 1 Phytophthora nicotianae isolate exposed to host genotype K326 Wz/- for one (G1) and five generations (G5). Percent root rot was rated manually 28 days post inoculation on a scale of 0 to 100 . Significant differences between $\mathrm{G} 1$ and $\mathrm{G} 5$ inoculations for each variety are indicated by "*”. 
support specific pathogen adaptation to $W z$-containing genotypes after exposure to this source of resistance for as few as five host generations. On $W z$ genotypes, G5 isolates were able to cause significantly greater amounts of disease and in a shorter period of time compared with G1 isolates. While it is often assumed that R-genes confer race-specific, complete resistance, there are many exceptions (Niks et al. 2015). In many host pathosystems, it is common for R-genes to result in incomplete or partial resistance in the host (Andaya and Ronald 2003; Franckowiak et al. 1997; Lawrence et al. 1995; Parniske et al. 1997; Smith and Hulbert 2005; Stewart et al. 2003). For example, barley variety Trumpf shows incomplete expression of resistance to avirulent isolate Israel 202 of $P$. hordei conferred by one major R-gene, Rph9. $z$ (Franckowiak et al. 1997).

Increased aggressiveness after exposure to host varieties with high levels of partial resistance has been reported in many pathosystems. For $P$. nicotianae on tobacco, increases in secondary inoculum production and aggressiveness have been reported after exposure to varieties with high levels of partial resistance (Dukes and Apple 1961; Sullivan et al. 2005a). Observed increases in pathogen aggressiveness were gradual, however, resulting in a slow erosion of partial resistance derived from Fla 301 over time.

In this study, we demonstrated that $W z$ is unlike the complete resistance conferred by the $P h p$ gene. $W z$ confers tissue-specific resistance (only root) to race 0 and race 1 of $P$. nicotianae while Php confers complete resistance for all plant parts to only race 0 . In addition, $W z$ does not provide immunity to the pathogen; some disease developed on $W z$ plants following inoculation with nonadapted isolates, which has also been observed in field studies (Drake et al. 2015). At the current time, we do not have evidence to indicate that $W z$ confers a high level of resistance via a gene-for-gene mechanism. However, results suggest the $W z$ gene selects for variants in the pathogen population that render resistance less effective after relatively few generations of selection. Deploying $\mathrm{Wz}$ in combination with $P h p$ in genetic backgrounds with a medium to high level of polygenic resistance may slow pathogen adaptation and prove to be the most effective means of developing black shank-resistant tobacco cultivars. DNA markers for qualitative black shank resistance genes (Drake and Lewis 2013; Johnson et al. 2002), in addition to markers linked to QTLs associated with black shank resistance (Drake-Stowe et al. 2017; Vontimitta and Lewis 2012a; Xiao et al. 2013), make it possible to pyramid multiple resistance genes into a single cultivar. In a Brassica napus-Leptosphaeria maculans pathosystem, stacking a qualitative R-gene with quantitative polygenic resistance extended resistance provided by the $R \operatorname{lm} 6$ gene 3 years longer than when the gene was deployed in a susceptible background (Brun et al. 2010). Combining multiple sources of resistance could potentially slow the development of $P$. nicotianae isolates with alternative virulence profiles, as mutations in a number of different avirulence genes would need to accumulate before a population could cause high levels of disease in these plants (Michelmore et al. 2013; Vanderplank 1984).

\section{Acknowledgments}

The authors would like to recognize Arlene Mendoza-Moran and Rob Fong for their excellent technical assistance. This research was supported by grants from Philip Morris International, the Tobacco Education and Research Council, Inc., the North Carolina Tobacco Research Commission, and R. J. Reynolds Tobacco Company.

\section{Literature Cited}

Andaya, C. B., and Ronald, P. C. 2003. A catalytically impaired mutant of the rice Xa21 receptor kinase confers partial resistance to Xanthomonas oryzae pv oryzae. Physiol. Mol. Plant Pathol. 62:203-208.

Apple, J. L. 1962. Physiological specialization within Phytophthora parasitica var. nicotianae. Phytopathology 52:351-354.

Apple, J. L. 1967. Occurrence of race 1 of Phytophthora parasitica var. nicotianae in North Carolina and its implications in breeding for disease resistance. Tob. Sci. 11:79-83.

Brun, H. A., Chevre, M., Fitt, B. D. L., Powers, S., Besnard, A. L., Ermel, M., Huteau, V., Marquer, B., Eber, F., Renard, M., and Andrivon, D. 2010. Quantitative resistance increases the durability of qualitative resistance to Leptosphaeria maculans in Brassica napus. New Phytol. 185:285-299.

Chaplin, J. F. 1962. Transfer of black shank resistance from Nicotiana plumbaginifolia to flue-cured N. tabacum. Tob. Sci. 6:184-189.

Chaplin, J. F. 1966. Comparison of tobacco black shank (Phytophthora parasitica var. nicotianae) resistance from four sources. Tob. Sci. 10:55-58.
Cowger, C., and Mundt, C. C. 2002. Aggressiveness of Mycosphaerella graminicola isolates from susceptible and partially resistant wheat cultivars. Phytopathology 92:624-630.

Csinos, A. S. 1999. Stem and root resistance to black shank. Plant Dis. 83:777-780.

Csinos, A. S., and Bertrand, P. F. 1994. Distribution of Phytophthora parasitica var. nicotianae races and their sensitivity to metalaxyl in Georgia. Plant Dis. 78:471-474.

Delmotte, F., Mestre, P., Schneider, C., Kassemeyer, H., Kozma, P., RichartCervera, S., Rouxel, M., and Deliére, L. 2014. Rapid and multiregional adaptation to host partial resistance in a plant pathogenic oomycete: Evidence from European populations of Plasmopara viticola, the causal agent of grapevine downy mildew. Infect. Genet. Evol. 27:500-508.

Drake, K. E., and Lewis, R. S. 2013. An introgressed Nicotiana rustica genomic region confers resistance to Phytophthora nicotianae in cultivated tobacco. Crop Sci. 53:1366-1374.

Drake, K. E., Moore, J. M., Bertrand, P., Fortnum, B., Peterson, P., and Lewis, R. S. 2015. Black shank resistance and agronomic performance of flue-cured tobacco lines and hybrids carrying the introgressed Nicotianae rustica region, Wz. Crop Sci. 55:79-86.

Drake-Stowe, K., Bakaher, N., Goepfert, S., Philippon, B., Mark, R., Peterson, P., and Lewis, R. S. 2017. Multiple disease resistance loci affect soil-borne disease resistance in tobacco (Nicotiana tabacum L.). Phytopathology 107:1055-1061.

Dukes, P. D., and Apple, J. L. 1961. Influence of host passage on virulence of Phytophthora parasitica var. nicotianae. Plant Dis. Rept. 45:362-365.

Ferrin, D. M., and Mitchell, D. J. 1986. Influence of initial density and distribution of inoculum on the epidemiology of tobacco black shank. Phytopathology 76: 1153-1158.

Franckowiak, J. D., Jin, Y., and Steffenson, B. J. 1997. Recommended allele symbols for leaf rust resistance genes in barely. Barley Genet. Newsl. 27:36-44

Gallup, C. A., and Shew, H. D. 2010. Occurrence of race 3 of Phytophthora nicotianae in North Carolina, the causal agent of black shank of tobacco. Plant Dis. 94:557-562.

Gallup, C. A., Sullivan, M. J., and Shew, H. D. 2006. Black Shank of Tobacco. The Plant Health Instructor.

Heggestad, H., and Lautz, W. 1957. Some results of studies on resistance to tobacco black shank. Phytopathology 47:452.

Johnson, E. S., Wolff, M. S., and Wernsman, E. A. 2002. Marker-assisted selection for resistance to black shank disease in tobacco. Plant Dis. 86: 1303-1309.

Jones, K. J., and Shew, H. D. 1995. Early season root production and zoospore infection of varieties of flue-cured tobacco that differ in level of partial resistance to Phytophthora nicotianae. Plant Soil 172:55-61.

Kannwischer, M. E., and Mitchell, D. J. 1978. The influence of a fungicide on the epidemiology of black shank of tobacco. Phytopathology 68:1760-1765.

Kramer, C. Y. 1956. Extension of multiple range tests to group means with unequal number of replications. Biometrics 12:307-310.

Lawrence, G. J., Finnegan, E. J., Ayliffe, M. A., and Ellis, J. G. 1995. The L6 gene for flax rust resistance is related to the Arabidopsis bacterial resistance gene RPS2 and the tobacco viral resistance gene $N$. Plant Cell 7:1195-1206.

Lehman, J. S., and Shaner, G. 1997. Selection of populations of Pucinnia recondite f. sp. Trici for shortened latent period on a partially resistant wheat cultivar. Phytopathology 87:170-176.

Leonard, K. J. 1969. Selection in heterogeneous populations of Puccinia graminis f. sp. avenae. Phytopathology 59:1851-1857.

Lucas, G. B. 1975. Diseases of Tobacco, 3rd Ed. Biological Consulting Associates, Raleigh, NC.

Madden, L. V., Hughes, G., and van den Bosch, F. 2007. The study of plant disease epidemics. APS Press, St. Paul, MN.

McCorkle, K. L. 2016. Characterization of the tobacco pathogen Phytophthora nicotianae and its ability to adapt to host resistance. Retrieved from NC State Theses and Dissertations Repository. https://repository.lib.ncsu.edu/handle/ $1840.20 / 22904$

McCorkle, K. L., Lewis, R. S., and Shew, H. D. 2013. Quantifying components of resistance to Phytophthora nicotianae in doubled-haploid tobacco breeding lines derived from the resistant tobacco variety Beinhart 1000. Plant Dis. 97: 252-258.

McCorkle, K. L., Lewis, R. S., and Shew, H. D. 2015. Adaptation to host resistance genes by Phytophthora nicotianae (Abstr.). Phytopathology 105: S4.91.

McDonald, B. A., and Linde, C. 2002. Pathogen population genetics, evolutionary potential, and durable resistance. Annu. Rev. Phytopathol. 40:349-379.

McIntyre, J. L., and Taylor, G. S. 1976. Screening tobacco seedlings for resistance to Phytophthora parasitica var. nicotianae. Phytopathology 66:70-73.

McIntyre, J. L., and Taylor, G. S. 1978. Race 3 of Phytophthora parasitica var nicotianae. Phytopathology 68:35-38.

Michelmore, R. W., Christopoulou, M., and Caldwell, K. S. 2013. Impacts of resistance gene genetics, function, and evolution on a durable future. Annu. Rev. Phytopathol. 51:291-319.

Montarry, J., Cartier, E., Jacquemond, M., Palloix, A., and Moury, B. 2012. Virus adaptation to quantitative plant resistance: erosion or breakdown? J. Evol. Biol. 25:2242-2252.

Nielsen, M. T. 1992. Sources of resistance to black shank and black root rot diseases. CORESTA Inf. Bull. 3/4:144-150. 
Niks, R. E., Qi, X., and Marcel, T. C. 2015. Quantitative resistance to biotrophic filamentous plant pathogens: concepts, misconceptions, and mechanisms. Annu. Rev. Phytopathol. 53:445-70.

Parniske, M., Hammond-Kosack, K. E., Golstein, C., Thomas, C. M., Jones, D. A., Harrison, K., Wulff, B. B. H., and Jones, J. D. G. 1997. Novel disease resistance specificities result from sequence exchange between tandemly repeated genes at the Cf-4/9 locus of tomato. Cell 91:821-832.

Phillips, M. S., and Blok, V. C. 2008. Selection for reproductive ability in Globodera pallida populations in relations to quantitative resistance from Solanum vernei and S. tuberosum spp. andigena CPC2802. Plant Pathol. 57:573-580.

Shew, H. D. 1983. Effects of soil matrix potential on infection of tobacco by Phytophthora parasitica var. nicotianae. Phytopathology 73:1160-1163.

Shew, H. D., and Lucas, G. B. 1991. Compendium of Tobacco Diseases. APS Press, The American Phytopathological Society, St. Paul, MN.

Smith, S. M., and Hulbert, S. H. 2005. Recombination events generating a novel $R p 1$ race specificity. Mol. Plant-Microbe Interact. 18:220-228.

Smith, T. E., and Clayton, E. E. 1948. Resistance to bacterial wilt and black shank in flue-cured tobacco. Phytopathology 38:227-229.

Stewart, H. E., Bradshaw, J. E., and Pande, B. 2003. The effect of the presence of Rgenes for resistance to late blight (Phytophthora infestans) of potato (Solanum tuberosum) on the underlying level of field resistance. Plant Pathol. 52:193-198.

Sullivan, M. J., Melton, T. A., and Shew, H. D. 2005a. Fitness of races 0 and 1 of Phytophthora parasitica var. nicotianae. Plant Dis. 89:1220-1228.

Sullivan, M. J., Melton, T. A., and Shew, H. D. 2005b. Managing the race structure of Phytophthora parasitica var. nicotianae with cultivar rotation. Plant Dis. 89: 1285-1294.

Tedford, E. C., and Nielsen, M. T. 1990. Recurrent selection for black shank resistance in a synthetic tobacco population. Tob. Sci. 34:70-73.

Tisdale, W. B. 1931. Development of cigar wrapper tobacco resistance to black shank (Phytophthora nicotianae Breda de Haan). Tech. Bull. 226, University of Florida Agricultural Experiment Station.
Valleau, W. D., Stokes, G. W., and Johnson, E. M. 1960. Nine years' experience with the Nicotiana longiflora factor for resistance to Phytophthora parasitica var. nicotianae in the control of black shank. Tob. Sci. 4:92-94.

van Jaarsveld, E., Wingfeld, M. J., and Drenth, A. 2002. Evaluation of tobacco varieties for resistance to races of Phytophthora nicotianae in South Africa. J. Phytopathol. 150:456-462.

Vanderplank, J. E. 1984. Disease Resistance in Plants, 2nd Ed. Academic Press, Orlando, FL.

Villaréal, L. M. M. A., and Lannou, C. 2000. Selection for increased spore efficacy by host genetic background in a wheat powdery mildew population. Phytopathology 90:1300-1306.

Vontimitta, V., and Lewis, R. S. 2012a. Mapping of quantitative trait loci affecting resistance to Phytophthora nicotianae in tobacco (Nicotiana tabacum L.) line Beinhart-1000. Mol. Breed. 29:89-98.

Vontimitta, V., and Lewis, R. S. 2012b. Growth chamber evaluation of a tobacco 'Beinhart 1000 ' $\times$ 'Hicks' mapping population for quantitative trait loci affecting resistance to multiple races of Phytophthora nicotianae. Crop Sci. 52:91-98

Wernsman, E. A., Matzinger, D. F., and Powell, N. T. 1974. Genetic investigations of intraspecific and interspecific sources of black shank resistance in tobacco. Tob. Sci. 18:15-18.

Wills, W. H., and Moore, L. D. 1971. Response of some cultivars and lines of tobacco to stem inoculation with Phytophthora parasitica var. nicotianae. Tob. Sci. 15:51-53.

Woodend, J. J., and Mudzengerere, E. 1992. Inheritance of resistance to wildfire and angular leaf spot derived from Nicotiana rustica var. Brasilia. Euphytica 64:149-156.

Xiao, B., Drake, K. E., Vontimitta, V., Tong, Z., Zhang, X., Li, M., Leng, X., Li Y., and Lewis, R. S. 2013. Location of genomic regions contributing to Phytophthora nicotianae resistance in tobacco cultivar Florida 301. Crop Sci. 53:473-481. 